\title{
Thermal, Crystallization, and Biodegradation Behavior of Poly(3-hydroxybutyrate) Blends with Poly(butylene succinate-co-butylene adipate) and Poly(butylene succinate-co-e-caprolactone)
}

\author{
Yong He, Takashi Masuda,* Amin CaO, Naoko Yoshie, \\ Yoshiharu DoI, ${ }^{* *}$ and Yoshio InouE ${ }^{\dagger}$ \\ Department of Biomolecular Engineering, Tokyo Institute of Technology, \\ Nagatsuta 4259, Midori-ku, Yokohama 226-8501, Japan \\ * Department of Organic Materials, National Institute of Materials and Chemical Research, \\ Agency of Industrial Science and Technology, Ministry of International Trade and \\ Industry, 1-1 Higashi, Tsukuba Ibaraki 305-8565, Japan \\ ** Polymer Chemistry Laboratory, The Institute of Physical and Chemical Research (RIKEN), \\ Hirosawa, Wako-shi, Saitama 351-0198, Japan
}

(Received September 4, 1998)

\begin{abstract}
Morphologies, some physical properties, and biodegradability were investigated for the binary blends of natural poly(3-hydroxybutyrate) $[\mathrm{P}(3 \mathrm{HB})]$ with chemosynthetic poly(butylene succinate-co-butylene adipate) (PBSA) and poly(butylene succinate-co- $\varepsilon$-caprolactone) (PBSC) prepared using a simple casting procedure. The DSC thermogram of each blend system revealed two distinct glass transitions independent of blend composition. The radial growth rate of $\mathrm{P}(3 \mathrm{HB})$ spherulite in the blends, observed on a polarizing microscopy, almost kept constant in the blends with $\mathrm{P}(3 \mathrm{HB})$ content ranged from $50 \mathrm{wt} \%$ to $100 \mathrm{wt} \%$. These results indicate that $\mathrm{P}(3 \mathrm{HB})$ and $\mathrm{PBSA}$, and $\mathrm{P}(3 \mathrm{HB})$ and $\mathrm{PBSC}$ are immiscible in the amorphous state. The enzymatic degradation of blend film was carried out in phosphate buffer $(\mathrm{pH} 7.5)$ at $37^{\circ} \mathrm{C}$ in the presence of $\mathrm{P}(3 \mathrm{HB})$ depolymerase purified from Alcaligenes faecalis T1. The degradation behavior of blends was monitored by observing UV spectra, measurement of weight-loss and NMR analysis. As a general, the weight-loss rates of blends increased with the increase of $\mathrm{P}(3 \mathrm{HB})$ content except the blends contained $90 \mathrm{wt} \% \mathrm{P}(3 \mathrm{HB})$ in which a weight-loss was about three times faster than that of pure $\mathrm{P}(3 \mathrm{HB})$ films. After the beginning of degradation, the content of $\mathrm{P}(3 \mathrm{HB})$ in films decreased faster than those of blend partners. The biodegradability of aliphatic polyester is suggested to be controllable by blending.

KEY WORDS Blends / Miscibility / Biodegradation / Poly(3-hydroxybutyrate) / Poly(butylene succinate-co-butylene adipate) / Poly(butylene succinate-co- $\varepsilon$-caprolactone) /
\end{abstract}

Bacterially produced poly(3-hydroxybutyrate) $[\mathrm{P}(3 \mathrm{HB})]$ has attracted much attention as biodegradable plastics. ${ }^{-3}$ It possesses general characteristics comparable to those of isotactic polypropylene and shows excellent biodegradability. However, the brittleness, narrow processability window and high price of $\mathrm{P}(3 \mathrm{HB})$ limit its application. One approach to improve the properties of $\mathrm{P}(3 \mathrm{HB})$ is to incorporate other hydroxyalkanoate units into the polymer backbone. In fact various copolymers containing 3-hydroxybutyrate unit have been biosynthesized or chemosynthesized ${ }^{1,4-6}$ and their synthesis, physical properties and biodegradation behavior have been extensively studied. ${ }^{7,8}$ Comparing to copolymerization, blending $\mathrm{P}(3 \mathrm{HB})$ with other polymers may be more economical and more feasible to modify the physical properties, to improve the processabilities and to lower the production cost.

So far, a variety of blends containing $\mathrm{P}(3 \mathrm{HB})$ have been studied, including binary blends with poly(vinyl acetate) (PVAc), ${ }^{9-10}$ poly(methyl methacrylate) (PMMA), ${ }^{11}$ poly(ethylene oxide) (PEO), ${ }^{12-15}$ poly(vinyl alcohol) (PVA), ${ }^{16}$ poly(lactide) (PLA), ${ }^{17-19}$ poly $(\varepsilon-$ caprolactone) (PCL), ${ }^{10,20}$ and poly(3-hydroxybutyrateco-3-hydroxyvalerate) (P(3HB-3HV)). ${ }^{21-23}$ The blends of $\mathrm{P}(3 \mathrm{HB})$ with natural biodegradable polysaccharides, such as cellulose and starch derivatives, chitin, and chitosan have been also reported. ${ }^{24-27}$ Among these blends, $\mathrm{P}(3 \mathrm{HB}) / \mathrm{PVAc},{ }^{9-10} \mathrm{P}(3 \mathrm{HB}) / \mathrm{PEO},{ }^{12}$ and $\mathrm{P}(3 \mathrm{HB}) /$

\footnotetext{
† To whom correspondence should be addressed.
}

PVA $^{16}$ were reported to be miscible over the whole composition range in the amorphous state; The miscibility of $\mathrm{P}(3 \mathrm{HB}) / \mathrm{PLA}^{18}$ and $\mathrm{P}(3 \mathrm{HB}) / \mathrm{P}(3 \mathrm{HB}-3 \mathrm{HV})$ blends ${ }^{21-23}$ was dependent on the molecular weight of PLA and the fraction of $3 \mathrm{HV}$ unit, respectively; $\mathrm{P}(3 \mathrm{HB})$ / $\mathrm{PMMA}^{11}$ and $\mathrm{P}(3 \mathrm{HB}) /$ cellulose ester blends ${ }^{25}$ were miscible with $\mathrm{P}(3 \mathrm{HB})$ content below $20 \mathrm{wt} \%$ and $50 \mathrm{wt} \%$, respectively; $\mathrm{P}(3 \mathrm{HB}) / \mathrm{PCL}$ blend ${ }^{10,20}$ was found to be immiscible independent of the blend composition.

As one of the most important properties for biodegradable polymer materials, the biodegradation properties of $\mathrm{P}(3 \mathrm{HB})$ and its copolymers have been investigated in many works. The biodegradability has been evaluated in soil, in river water, in seawater and in hydrolyzing enzyme solution. It has been made clear that the biodegradation behavior of $\mathrm{P}(3 \mathrm{HB})$ and its copolymers strongly depended on the condition of degradation, their comonomer compositions and solid-state structure. ${ }^{7,8}$ Comparing to $\mathrm{P}(3 \mathrm{HB})$ and its copolymers, there are only a little studies on the biodegradation behavior of $\mathrm{P}(3 \mathrm{HB})$ blends. The studies on $\mathrm{P}(3 \mathrm{HB}) /$ poly $(\beta$-propiolactone), $\mathrm{P}(3 \mathrm{HB}) /$ poly(ethylene adipate), and $\mathrm{P}(3 \mathrm{HB}) / \mathrm{P}(3 \mathrm{HB}-3 \mathrm{HV})$ blend systems $\mathrm{s}^{28}$ have revealed that the degradation rates of these blends in the presence of $\mathrm{P}(3 \mathrm{HB})$ depolymerase increase with the increase of $\mathrm{P}(3 \mathrm{HB})$ content, and that some blends with limited range of $\mathrm{P}(3 \mathrm{HB})$ content show the degradation rates larger than that of pure $\mathrm{P}(3 \mathrm{HB})$. More recent works indicated that chemosynthetic $\mathrm{P}(R, S-3 \mathrm{HB})$ underwent enzymatic attack when it blended with natural $\mathrm{P}(3 \mathrm{HB})^{29}$ 
Table I. The molecular structure, thermal properties, and molecular weights of polymer samples

\begin{tabular}{|c|c|c|c|c|c|}
\hline Sample & Molecular structure ${ }^{a}$ & $T_{\mathrm{m}} /{ }^{\circ} \mathrm{C}^{\mathrm{b}}$ & $T_{\mathrm{g}} /{ }^{\circ} \mathrm{C}^{\mathrm{b}}$ & $M_{w}{ }^{\mathrm{c}}$ & $M_{w} / M_{n}{ }^{\mathrm{c}}$ \\
\hline $\mathrm{P}(3 \mathrm{HB})$ & 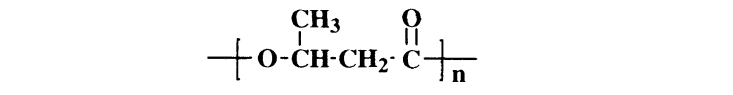 & 174 & 5 & $4.73 \times 10^{5}$ & 1.99 \\
\hline PBSA & 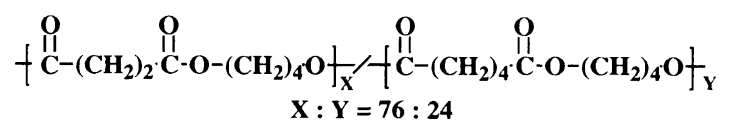 & 90 & -40 & $2.34 \times 10^{5}$ & 1.89 \\
\hline PBSC & 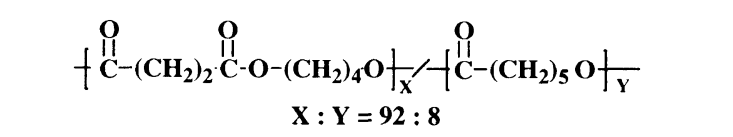 & 107 & -35 & $1.47 \times 10^{5}$ & 2.25 \\
\hline
\end{tabular}

${ }^{\mathrm{a}}$ Copolymer composition determined by ${ }^{1} \mathrm{H}$ NMR. ${ }^{\mathrm{b}}$ By measurements of DSC. ${ }^{\mathrm{c}} \mathrm{By}$ GPC in chloroform at $35^{\circ} \mathrm{C}$.

or $\mathrm{P}(3 \mathrm{HB}-3 \mathrm{HV})^{30}$ but it alone did not biodegrade.

The chemosynthetic poly(butylene succinate-co-butylene adipate) (PBSA) $)^{31,32}$ and poly(butylene succinateco- $\varepsilon$-caprolactone) (PBSC) are biodegradable polyesters with melting point of about $100^{\circ} \mathrm{C}$ and glass transition temperature of about $-40^{\circ} \mathrm{C}$. They show good processabilities and mechanical properties as an environmentally degradable resin and may be used for a wide range of agricultural, marine, and medical applications.

PBSA and PBSC should be good polymer components to be blended with $\mathrm{P}(3 \mathrm{HB})$ : first, binary blends of natural $\mathrm{P}(3 \mathrm{HB})$ with chemosynthetic PBSA and PBSC are completely degradable for all the components are biodegradable polyesters; second, PBSA and PBSC may enable the blends to possess good processabilities and mechanical properties as $\mathrm{P}(3 \mathrm{HB})$ may enable the blends to possess good biodegradability and biocompatibility, that is, the binary blends may possess good processabilities and mechanical properties as well as good biodegradability and biocompatibility; third, adding PBSA and PBSC will greatly lower the cost of $\mathrm{P}(3 \mathrm{HB})$ materials. Hence, in this study, it is expected to improve the properties and to widen the application range of $\mathrm{P}(3 \mathrm{HB})$ materials by means of blending $\mathrm{P}(3 \mathrm{HB})$ with PBSA and PBSC.

In this paper, on the one hand, we will focus on PBSA/P(3HB) blends(AB blends) and $\mathrm{PBSC} / \mathrm{P}(3 \mathrm{HB})$ blends ( $\mathrm{CB}$ blends) to investigate their morphologies, physical properties and biodegradability as a function of blend composition; on the other hand, we will try to found the relationships between morphologies, physical properties, and biodegradability, and to make clear the effect of $\mathrm{P}(3 \mathrm{HB})$ on the enzymatic degradation behavior of PBSA and PBSC.

\section{EXPERIMENTAL}

\section{Materials}

Bacterial $\mathrm{P}(3 \mathrm{HB})$ sample purchased from Aldrich Chemical Co. was used after purification by precipitation in ethanol from 1,2-dichloroethane solution. PBSA (Bionolle ${ }^{\circledR}-\# 3000$ ) was supplied by Showa Highpolymer Co. It was used as received.

PBSC sample was synthesized through a demethanol polymerization in a 21 round-bottomed stainless steel reactor equipped with a mechanical stirrer, thermocouple, and a product outlet nozzle for a pelletizer. The polymerization of dimethyl succinate $(4.32 \mathrm{~mol})$ and 1,4-butanediol (4.49 mol) with $\varepsilon$-caprolactone $(0.432 \mathrm{~mol})$ was undertaken in bulk at temperatures range from $160^{\circ} \mathrm{C}$ to $200^{\circ} \mathrm{C}$ in the presence of titanium tetraisopropoxide $(2.16 \mathrm{mmol})$ in an atmosphere of nitrogen. After about $90 \%$ of the theoretical amount of methanol was removed (about $4 \mathrm{~h}$ was required), the residual methanol was removed at $200-215^{\circ} \mathrm{C} / 67 \mathrm{~Pa}$ for $6 \mathrm{~h}$. PBSC was obtained as pellets in a yield of $595 \mathrm{~g}$.

The molecular weights of the three samples were characterized by a Tosoh HLC-8020 GPC system at $35^{\circ} \mathrm{C}$, chloroform was used as the eluent and polystyrene with a narrow molecular distribution was used as a standard to calibrate the curve. Table I lists the molecular structures, thermal properties, molecular weights, and polydispersities of the samples.

\section{Preparation of Blend}

The films of $\mathrm{PBSA} / \mathrm{P}(3 \mathrm{HB})(\mathrm{AB})$ and $\mathrm{PBSC} / \mathrm{P}(3 \mathrm{HB})$ (CB) blends were prepared by casting from $5 \mathrm{wt} \%$ chloroform solution, allowing the solvent to evaporate at room temperature an overnight, and then keeping under vacuum for further two days at $60^{\circ} \mathrm{C}$ and finally two weeks at room temperature.

\section{Differential Scanning Calorimetry}

Differential scanning calorimetry (DSC) analysis was performed to study miscibility and thermal behavior of the blends on a SEIKO DSC 220 system which connected with a workstation SSC5300. Samples packed in aluminum pans as casting films were first heated from $-100^{\circ} \mathrm{C}$ to $195^{\circ} \mathrm{C}$ at a heating rate of $20^{\circ} \mathrm{C} \mathrm{min}^{-1}$ (RUN 1). After keeping them at $195^{\circ} \mathrm{C}$ for $0.5 \mathrm{~min}$, samples were rapidly quenched to $-100^{\circ} \mathrm{C}$, and then they were again heated at a rate of $20^{\circ} \mathrm{C} \mathrm{min}^{-1}$ to $195^{\circ} \mathrm{C}$ (RUN $2)$. The melting temperatures $\left(T_{\mathrm{m}}\right)$ and crystallization temperatures $\left(T_{\mathrm{c}}\right)$ were determined from DSC endothermic and exothermic peaks, respectively. The glass transition temperature $\left(T_{\mathrm{g}}\right)$ was measured from the peak of DDSC (difference of differential scanning calorimetry) curves obtained by RUN 2. The values of melting enthalpy were calculated as the integrals of endothermal peaks.

\section{Polarizing Optical Microscopy}

Isothermal spherulite growth behavior was investigated on a polarized microscopy of Olympus BX90 equipped 
Table II. The thermal properties of AB blends

\begin{tabular}{|c|c|c|c|c|c|c|c|c|c|}
\hline \multirow{2}{*}{ Blend } & \multirow{2}{*}{$\begin{array}{c}\mathrm{P}(3 \mathrm{HB}) \\
\text { content } / w \mathrm{t} \%\end{array}$} & \multicolumn{2}{|c|}{$T_{\mathrm{g}} /{ }^{\circ} \mathrm{C}^{\mathrm{a}}$} & \multicolumn{2}{|c|}{$T_{\mathrm{m}} /{ }^{\circ} \mathrm{C}^{\mathrm{b}}$} & \multirow{2}{*}{$\begin{array}{c}T_{\mathrm{c}} /{ }^{\circ} \mathrm{C}^{\mathrm{a}} \\
\mathrm{P}(3 \mathrm{HB})\end{array}$} & \multicolumn{2}{|c|}{$\Delta H_{\mathrm{m}}\left(\text { blend } / \mathrm{J} \mathrm{g}^{-1}\right)^{\mathrm{b} \cdot \mathrm{c}}$} & \multirow{2}{*}{$\begin{array}{c}X_{\mathrm{c}} / \%^{\mathrm{b}} \\
\mathrm{P}(3 \mathrm{HB})\end{array}$} \\
\hline & & PBSA & $\mathrm{P}(3 \mathrm{HB})$ & PBSA & $\mathrm{P}(3 \mathrm{HB})$ & & PBSA & $\mathrm{P}(3 \mathrm{HB})$ & \\
\hline PBSA & 0 & -39.6 & & 89.7 & & & 72.5 & & \\
\hline $\mathrm{AB} 10$ & 10 & -39.6 & 5.1 & 91.7 & 173.9 & - $^{\mathrm{d}}$ & 59.6 & 6.55 & 44.9 \\
\hline AB25 & 25 & -40.1 & 5.0 & 90.8 & 174.3 & - $^{\mathrm{d}}$ & 50.0 & 18.9 & 51.8 \\
\hline $\mathrm{AB} 40$ & 40 & -38.9 & 5.4 & 89.7 & 174.2 & 57.9 & 38.5 & 31.3 & 53.6 \\
\hline AB50 & 50 & -39.7 & 5.3 & 89.1 & 174.2 & 56.5 & 32.7 & 42.5 & 58.2 \\
\hline $\mathrm{AB} 60$ & 60 & -41.9 & 5.3 & 89.5 & 174.4 & 56.4 & 24.2 & 53.3 & 60.8 \\
\hline AB75 & 75 & -43.7 & 4.7 & 83.4 & 175.0 & 54.4 & 12.8 & 63.6 & 58.1 \\
\hline $\mathrm{AB} 90$ & 90 & -44.5 & 5.3 & $-^{\mathrm{d}}$ & 174.2 & 55.1 & ${ }^{\mathrm{d}}$ & 76.7 & 58.4 \\
\hline $\mathrm{P}(3 \mathrm{HB})$ & 100 & & 6.3 & & 174.7 & 61.0 & & 86.1 & 59.0 \\
\hline
\end{tabular}

${ }^{a}$ Obtained from RUN 2. ${ }^{\mathrm{b}}$ Obtained from RUN 1. ${ }^{\mathrm{c}}$ Melting enthalpy per gram of blend. ${ }^{\mathrm{d}}$ No result available.

with a Mettler FP82HT hot stage. The samples were firstly heated to a temperature of $195^{\circ} \mathrm{C}$ and kept $1 \mathrm{~min}$, then cooled to the desired crystallization temperature with a rate of $20^{\circ} \mathrm{Cmin}^{-1}$. The growth rates were calculated as the slopes of the lines obtained by plotting the radius against the time.

\section{Enzymatic Degradation}

The enzyme $\mathrm{P}(3 \mathrm{HB})$ depolymerase was purified from Alcaligenes faecalis $\mathrm{T} 1$ as reported in a literature. ${ }^{33,34}$ The final protein concentration of enzyme after purification was $508 \mu \mathrm{g} \mathrm{ml}^{-1}$, and activity was estimated as 314 units $\mathrm{mg}^{-1}$. The enzymatic degradation of blend films was carried out at $37^{\circ} \mathrm{C}$ in $0.1 \mathrm{M}$ phosphate buffer $(\mathrm{pH}=7.5)$. The film of initial weights about $12 \mathrm{mg}$ and initial dimension $10 \times 10 \times 0.1 \mathrm{~mm}$ was placed in the small bottle containing $2.0 \mu \mathrm{l}$ enzyme solution and $1.0 \mathrm{ml}$ buffer solution. The reaction solution was incubated with shaking, and the films were removed after reaction for a period of time, washed with distilled water and dried to constant weight in vacuum before analysis. For each blend sample, three films were used and the average value of their weight-loss amounts was taken as the result.

A UV-Vis spectrometer (UV-2100, Shimadzu Co.) was employed to investigate the time dependence of the degradation behavior of pure PBSA, PBSC, AB50 blend and CB50 blend. It was observed at $37^{\circ} \mathrm{C}$ with the wavelength of $208 \mathrm{~nm}$.

${ }^{1} \mathrm{H}$ NMR spectra of $\mathrm{AB}$ and $\mathrm{CB}$ blends before and after the degradation were recorded in $\mathrm{CDCl}_{3}$ solution at $30^{\circ} \mathrm{C}$ to estimate the $\mathrm{P}(3 \mathrm{HB})$ content in the blend film after enzyme degradation. It carried on a JEOL GSX270 NMR spectrometer with $90^{\circ}$ pulse, acquisition time $0.904 \mathrm{~s}, 32 \mathrm{~K}$ data points, and 512 FID accumulations.

\section{RESULTS AND DISCUSSION}

\section{Thermal Behaviors}

As shown in Table II, the AB blends show two distinct glass transitions temperature, $T_{\mathrm{g}} \mathrm{s}$. The lower and the higher ones correspond to PBSA and $\mathrm{P}(3 \mathrm{HB})$ component, respectively. There exist little variations in $T_{\mathrm{g}}$ values with blend composition and almost all the $T_{\mathrm{g}}$ values for the blends agreed well within the experimental error with those for respective pure components. These results suggest that the AB blends are immiscible systems in the amorphous state.

As to the CB blends, the results are almost the same 186 as those for the AB blends except a little difference. The CB blends also show two distinct $T_{\mathrm{g}}$ values but the lower and the higher $T_{\mathrm{g}} \mathrm{s}$, which correspond to PBSC and $\mathrm{P}(3 \mathrm{HB})$ components, respectively, show a little increase with the increase of $\mathrm{P}(3 \mathrm{HB})$ content in the blend (Table III). In other words, the $T_{\mathrm{g}}$ values of PBSC and $\mathrm{P}(3 \mathrm{HB})$ components in blends fall between those of pure PBSC and pure $\mathrm{P}(3 \mathrm{HB})$. This behavior may imply some degrees of compatibility between the two components. However, the blend should essentially be immiscible in the amorphous state because of existence of two distinct glass transitions.

In RUN 1 of DSC measurements, the melting temperatures $T_{\mathrm{m}} \mathrm{s}$ of PBSA and $\mathrm{P}(3 \mathrm{HB})$ components in the $\mathrm{AB}$ blends appear at relatively constant temperature of $90 \pm 2{ }^{\circ} \mathrm{C}$ and $174 \pm 1^{\circ} \mathrm{C}$, respectively, independent of blend compositions (Table II). In RUN 2, they appear at $91 \pm 1{ }^{\circ} \mathrm{C}$ and $172 \pm 1{ }^{\circ} \mathrm{C}$, respectively (the data were not listed).

Similar melting features were also found in the $\mathrm{CB}$ blends. The $T_{\mathrm{m}}$ values of $\mathrm{PBSC}$ and $\mathrm{P}(3 \mathrm{HB})$ components appear at almost constant temperatures independent of blend compositions. In either RUN 1 or RUN 2 they are $107 \pm 2^{\circ} \mathrm{C}$ and $174 \pm 2^{\circ} \mathrm{C}$ for PBSC and $\mathrm{P}(3 \mathrm{HB})$ components, respectively (Table III, the data for RUN 2 were not listed)

The $T_{\mathrm{m}} \mathrm{s}$ observed here are not equilibrium points and not those of samples crystallized isothermally. Considering all the samples have the same thermal history, the independence of $T_{\mathrm{m}}$ values on blends composition should indicate the independence of equilibrium point on composition. It can lead a conclusion that there are little interaction between the two components in the $\mathrm{AB}$ and the CB blends, which is well consistent with the conclusion derived from the $T_{\mathrm{g}}$ measurements that the two kinds of blends are immiscible.

In RUN 2, the crystallization temperature of $\mathrm{P}(3 \mathrm{HB})$ component in the $\mathrm{AB}$ blends appears at about $56^{\circ} \mathrm{C}$ independent of $\mathrm{P}(3 \mathrm{HB})$ content (Table II). However in the $\mathrm{CB}$ blends it increases from $48.6^{\circ} \mathrm{C}$ to $61.0^{\circ} \mathrm{C}$ with the $\mathrm{P}(3 \mathrm{HB})$ content from $25 \mathrm{wt} \%$ to $90 \mathrm{wt} \%$ (Table III), which accords with the fact that the glass transition temperature of $\mathrm{P}(3 \mathrm{HB})$ component increases a little with the increase of $\mathrm{P}(3 \mathrm{HB})$ content in the blend.

The melting enthalpy $(\Delta H)$ corresponding to each component in the $\mathrm{AB}$ or $\mathrm{CB}$ blends increases with the increase of its content in the blends (Tables II and III).

The crystallinity $\left(X_{\mathrm{c}}\right)$ of $\mathrm{P}(3 \mathrm{HB})$ phase can be calcu- 
Properties and Biodegradation of Polyester Blends

Table III. The thermal properties of CB blends

\begin{tabular}{|c|c|c|c|c|c|c|c|c|c|}
\hline \multirow{2}{*}{ Blend } & \multirow{2}{*}{$\begin{array}{c}\mathrm{P}(3 \mathrm{HB}) \\
\text { content } / \mathrm{wt} \%\end{array}$} & \multicolumn{2}{|c|}{$T_{\mathrm{g}}{ }^{\circ} \mathrm{C}^{\mathrm{a}}$} & \multicolumn{2}{|c|}{$T_{\mathrm{m}} / \mathrm{C}^{\mathrm{b}}$} & \multirow{2}{*}{$\begin{array}{c}T_{\mathrm{c}} /{ }^{\circ} \mathrm{C}^{\mathrm{a}} \\
\mathrm{P}(3 \mathrm{HB})\end{array}$} & \multicolumn{2}{|c|}{$\Delta H_{\mathrm{m}}\left(\text { blend } / \mathbf{J} \mathrm{g}^{-1}\right)^{\mathrm{b}, \mathrm{c}}$} & \multirow{2}{*}{$\begin{array}{l}X_{\mathrm{c}} / \%{ }^{\mathrm{b}} \\
\mathrm{P}(3 \mathrm{HB})\end{array}$} \\
\hline & & PBSC & $\mathrm{P}(3 \mathrm{HB})$ & PBSC & $\mathrm{P}(3 \mathrm{HB})$ & & PBSC & $\mathrm{P}(3 \mathrm{HB})$ & \\
\hline CB 10 & 10 & -35.2 & 1.8 & 105.3 & 172.9 & $-^{\mathrm{d}}$ & 85.8 & 7.69 & 52.7 \\
\hline CB25 & 25 & -34.1 & 2.8 & 108.6 & 174.0 & 48.6 & 68.6 & 19.0 & 52.1 \\
\hline CB40 & 40 & -34.1 & 3.2 & 107.8 & 173.4 & 53.5 & 47.9 & 32.9 & 56.3 \\
\hline CB50 & 50 & -33.2 & 3.9 & 109.0 & 175.0 & 55.0 & 44.1 & 42.2 & 58.1 \\
\hline CB60 & 60 & ${ }^{\mathrm{d}}$ & 4.1 & 107.4 & 174.1 & 54.3 & 31.1 & 51.5 & 58.8 \\
\hline CB75 & 75 & $-^{\mathrm{d}}$ & 4.8 & 106.6 & 175.6 & 56.5 & 16.5 & 62.6 & 57.2 \\
\hline CB90 & 90 & $L^{\mathrm{d}}$ & 6.5 & - d & 176.4 & 61.0 & d & 73.7 & 56.1 \\
\hline $\mathrm{P}(3 \mathrm{HB})$ & 100 & & 6.3 & & 174.7 & 61.0 & & 86.1 & 59.0 \\
\hline
\end{tabular}

${ }^{\text {a }}$ Obtained from RUN 2. ${ }^{\text {b }}$ Obtained from RUN 1. ${ }^{\mathrm{c}}$ Melting enthalpy per gram of blend. ${ }^{\mathrm{d}}$ No result available.

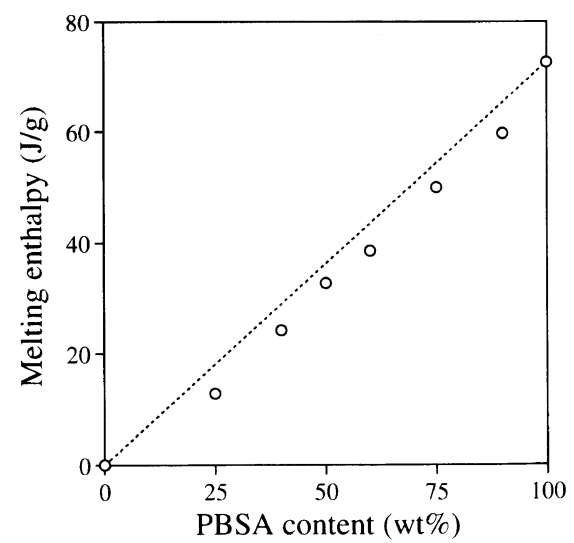

Figure 1. Plot of melting enthalpy of PBSA component versus its content in $\mathrm{AB}$ blend films.

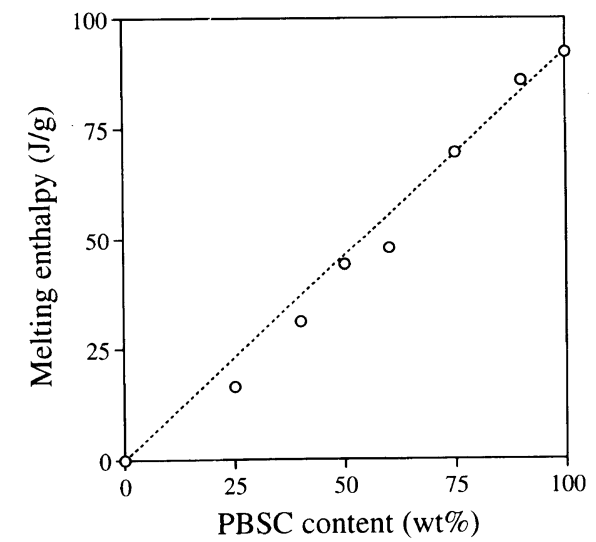

Figure 2. Plot of melting enthalpy of PBSC component versus its content in CB blend films.

lated by the following equation:

$$
X_{\mathrm{c}}=\Delta H /\left(\Delta H^{\mathrm{o}} \times W_{\mathbf{P}(3 \mathrm{HB})}\right)
$$

where $\Delta H^{\circ}$ is the thermodynamic melting enthalpy per gram of $\mathrm{P}(3 \mathrm{HB})\left(146.6 \mathrm{~J} \mathrm{~g}^{-135}\right) . \Delta H\left(\mathrm{~J} \mathrm{~g}^{-1}\right)$ is the apparent melting enthalpy corresponding to $\mathrm{P}(3 \mathrm{HB})$ component and $W_{\mathrm{P}(3 \mathrm{HB})}$ is the weight content of $\mathrm{P}(3 \mathrm{HB})$ in the blend.

In the $\mathrm{AB}$ blends, the crystallinity of $\mathrm{P}(3 \mathrm{HB}), X_{\mathrm{c}}$ (RUN 1), remains constant of about $59.0 \mathrm{wt} \%$ for the blends with $\mathrm{P}(3 \mathrm{HB})$ content larger than $50.0 \mathrm{wt} \%$ (Table II). This result indicates that the PBSA phase has little effect on the crystallization kinetics of $\mathrm{P}(3 \mathrm{HB})$ phase in this $\mathrm{P}(3 \mathrm{HB})$ content range. Below this content (critical

Polym. J., Vol. 31, No. 2, 1999

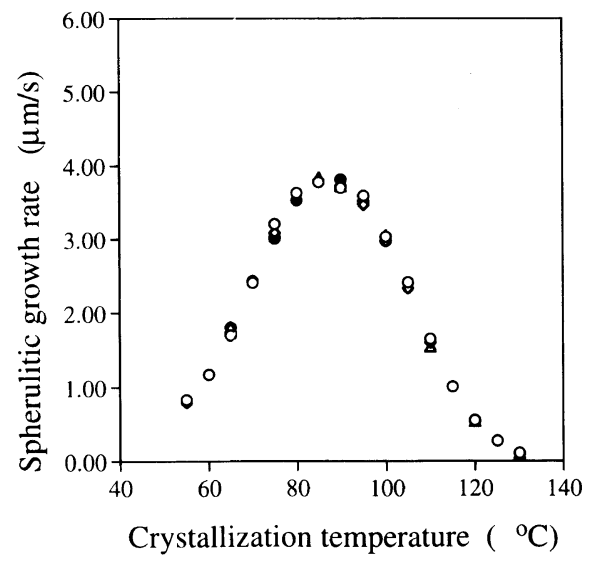

Figure 3. Spherulitic growth rates for pure $\mathrm{P}(3 \mathrm{HB})$ and $\mathrm{AB}$ blends: (O) $\mathrm{P}(3 \mathrm{HB}) ;(\diamond) \mathrm{AB} 90 ;(\triangle) \mathrm{AB} 75 ;(\bullet) \mathrm{AB} 50$.

$\mathrm{P}(3 \mathrm{HB})$ content $)$, the crystallinity of $\mathrm{P}(3 \mathrm{HB})$ increases with $\mathrm{P}(3 \mathrm{HB})$ content, which may be attributable to the elution effect of PBSA phase. The case for CB blends is the same except the critical $\mathrm{P}(3 \mathrm{HB})$ content decreases into about $40.0 \mathrm{wt} \%$ (Table III).

Figures 1 and 2 show the relationship between the melting enthalpies of PBSA and PBSC components and their contents in the blends, respectively. The values of melting enthalpy of PBSA component in the AB blends fall very close to the line which expresses the melting enthalpy of PBSA in the pure state (Figure 1). The same melting behavior was observed for PBSC component in the $\mathrm{CB}$ blends (Figure 2). So it may be considered that in these blend systems PBSA and PBSC can crystallize to the extent almost the same to that in the pure state.

\section{Crystallization Behaviour}

By polarizing microscopy, no apparent phase separation was found in the molten state $\left(195^{\circ} \mathrm{C}\right)$ of $\mathrm{AB}$ and $\mathrm{CB}$ blends for all of the compositions prepared and $\mathrm{P}(3 \mathrm{HB})$ was found to be able to crystallize isothermally with a spherulitic morphology even in the $\mathrm{P}(3 \mathrm{HB})$ content of $10 \mathrm{wt} \%$. At low crystallization temperature (below 80 and $95^{\circ} \mathrm{C}$ for PBSA and PBSC, respectively), the spherulites of PBSA and PBSC can also been observed. Comparing to the $\mathrm{P}(3 \mathrm{HB})$ spherulite, the radii of PBSA and PBSC spherulites were much smaller and the growth rates were too slow to be estimated.

Figures 3 and 4 showed the spherulitic growth rates for the $\mathrm{AB}$ and $\mathrm{CB}$ blends, respectively. The spherulitic 


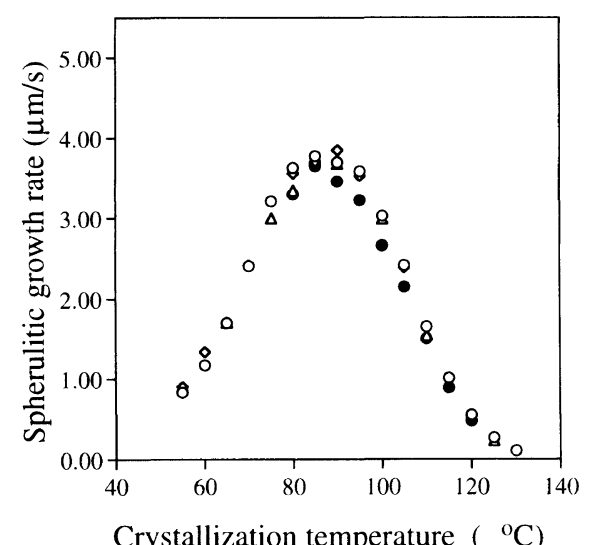

Figure 4. Spherulitic growth rates for pure $\mathrm{P}(3 \mathrm{HB})$ and $\mathrm{CB}$ blends: $(\bigcirc) \mathrm{P}(3 \mathrm{HB}) ;(\diamond) \mathrm{CB} 90 ;(\triangle) \mathrm{CB} 75$;

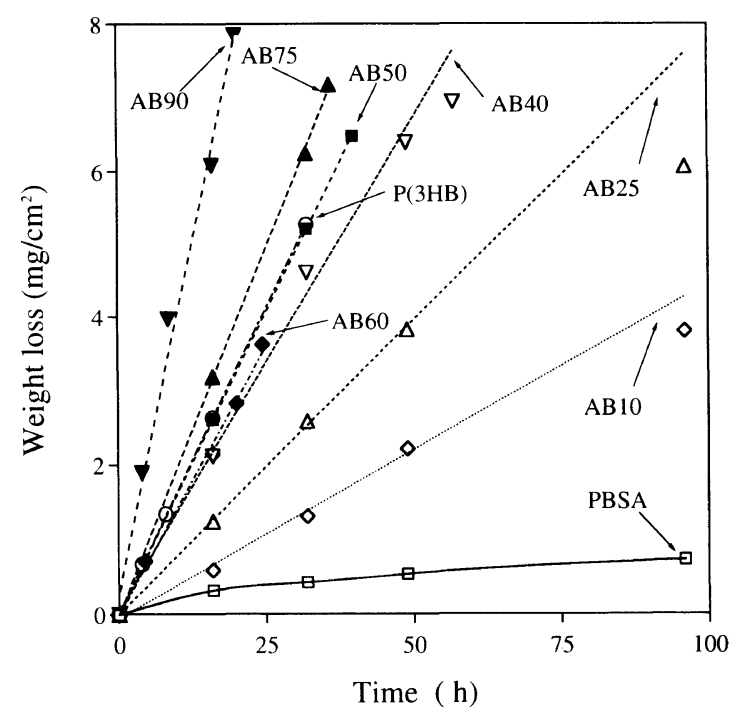

Figure 5. Plots of weight loss of $\mathrm{AB}$ blend films versus degradation time in the presence of $\mathrm{P}(3 \mathrm{HB})$ depolymerase at $37^{\circ} \mathrm{C}$ and $\mathrm{pH} 7.5$.

growth rate of $\mathrm{P}(3 \mathrm{HB})$ in $\mathrm{AB} 90, \mathrm{AB} 75, \mathrm{AB} 50$ blends was almost the same as that in the pure state within the crystallization temperature range from $55^{\circ} \mathrm{C}$ to $130^{\circ} \mathrm{C}$. For the $\mathrm{CB}$ blends, the case is similar to that of the $\mathrm{AB}$ blends, but in the CB50 blend the radial growth rate decreased. This result reconfirms that PBSA and PBSC molecules have little effect on the crystallization kinetics of $\mathrm{P}(3 \mathrm{HB})$ molecules in the blends.

\section{Enzymatic Degradation}

In Figure 5 is shown the relationship of weight-loss of the $\mathrm{AB}$ blends with elapsed time exposed to the enzyme solution. It indicates that there are three cases: (1) the first one is the AB10, AB25, and AB40 blend films which show the constant weight-loss rate at the first $48 \mathrm{~h}$, that is, the weight-loss increases linearly with the exposure time, while after that it decreases and the point diverges below the point expected from linear weight-loss; (2) the second one is the $\mathrm{AB}$ blends with $\mathrm{P}(3 \mathrm{HB})$ content larger than $40 \mathrm{wt} \%$ and pure $\mathrm{P}(3 \mathrm{HB})$ film, whose weight-loss rate increases proportionally with the exposure time; (3) the last one is the pure PBSA film which exhibits only a small weight-loss during whole period of the experiment. The occurrence of these three distinct cases may

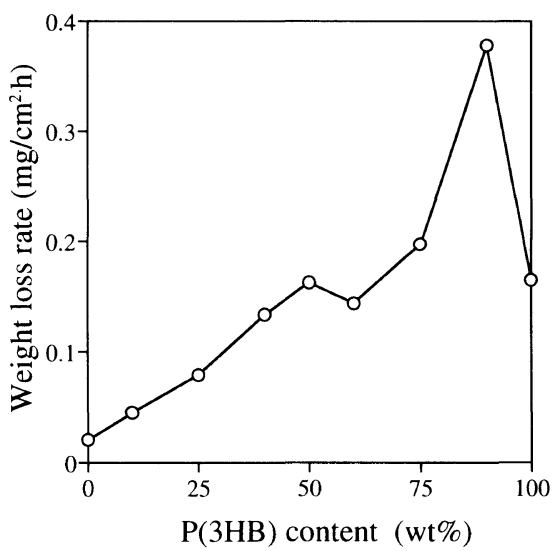

Figure 6. Plot of weight loss rates of $\mathrm{AB}$ blends versus $\mathrm{P}(3 \mathrm{HB})$ content in the presence of $\mathrm{P}(3 \mathrm{HB})$ depolymerase at $37^{\circ} \mathrm{C}$ and $\mathrm{pH} 7.5$.

come from the following two aspects: (i) the AB blend is immiscible systems over whole composition range; (ii) the $\mathrm{P}(3 \mathrm{HB})$ depolymerase is inactive to the hydrolysis of pure PBSA.

As a general rule, in a two-component immiscible blend systems each component will constitute a phase, which changes from a separate phase into a continuous phase with the increase of one's content in blend. As for AB blend systems, the case is the same. When AB blend films are etched with tetrahydrofuran (THF) (THF is a solvent for PBSA and a non-solvent for $\mathrm{P}(3 \mathrm{HB}))$, the films with low $\mathrm{P}(3 \mathrm{HB})$ content disappear completely with the solution become muddy while the films, with high $\mathrm{P}(3 \mathrm{HB})$ content remain the integrity and some holes (several micrometers) appear when observed under a polarizing optical microscopy-video system. These results indicate that $\mathrm{P}(3 \mathrm{HB})$ phase changes from a separate phase into a continuous phase and PBSA changes from a continuous phase into a separate phase with the increase of $\mathrm{P}(3 \mathrm{HB})$ content.

So it can be concluded that due to the aspect (i), in the blend films with lower $\mathrm{P}(3 \mathrm{HB})$ content, PBSA and $\mathrm{P}(3 \mathrm{HB})$ constitute the continuous and separate phases, respectively; and further due to the aspects (i) and (ii), the extent of $\mathrm{P}(3 \mathrm{HB})$ phase accessible for enzyme degradation decreases with the degradation time, resulting in the degradation behavior of case (1). On the other hand, in the $\mathrm{AB}$ blend with higher $\mathrm{P}(3 \mathrm{HB})$ content, $\mathrm{P}(3 \mathrm{HB})$ constitutes the continuous phase while PBSA constitutes the separate phase. With progressing the degradation of $\mathrm{P}(3 \mathrm{HB})$, the separate phase of PBSA will leave from the film and then the weight-loss rate of blend film should be rapid and remained constant as shown in the case (2).

Figure 6 shows the rates of weight-loss for the $A B$ blends with different $\mathrm{P}(3 \mathrm{HB})$ composition. For the pure $\mathrm{P}(3 \mathrm{HB})$ and blend films, the rates were estimated from the slopes of the lines shown in Figure 5. For the pure PBSA film it was estimated as the average weight-loss rate for the first $96 \mathrm{~h}$. It can be seen that the weight-loss rate increases with the increase of $\mathrm{P}(3 \mathrm{HB})$ content in blends, except for AB90 blend, which shows a much faster degradation. Similar trend, that the degradation by $\mathrm{P}(3 \mathrm{HB})$ depolymerase becomes faster with an increase of content of $\mathrm{P}(3 \mathrm{HB})$ component, has been also found for $\mathrm{P}(3 \mathrm{HB}) / \mathrm{PPL}, \mathrm{P}(3 \mathrm{HB}) / \mathrm{PEA}$, and $\mathrm{P}(3 \mathrm{HB}) / \mathrm{P}(3 \mathrm{HB}-$ 


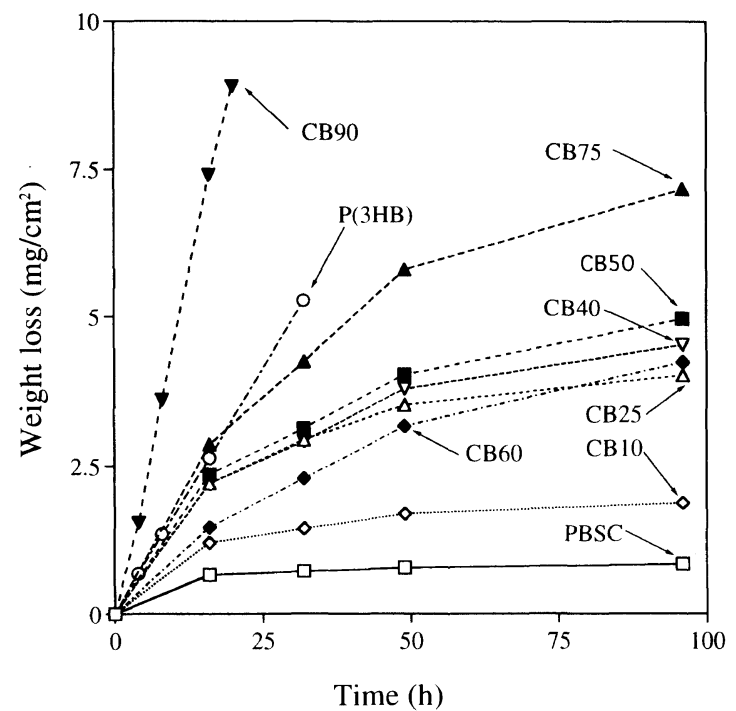

Figure 7. Plots of weight loss of $\mathrm{CB}$ blend films versus degradation time in the presence of $\mathrm{P}(3 \mathrm{HB})$ depolymerase at $37^{\circ} \mathrm{C}$ and $\mathrm{pH} 7.5$.

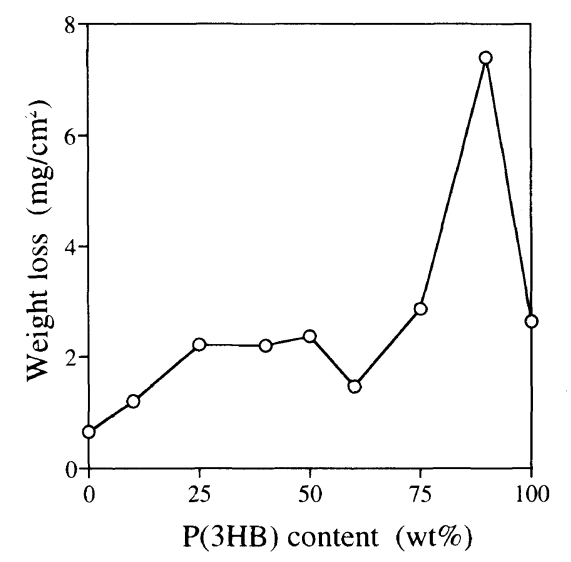

Figure 8. Plot of weight loss of $\mathrm{CB}$ blends versus $\mathrm{P}(3 \mathrm{HB})$ content for the first $16 \mathrm{~h}$ in the presence of $\mathrm{P}(3 \mathrm{HB})$ depolymerase at $37^{\circ} \mathrm{C}$ and $\mathrm{pH}$ 7.5 .

$3 \mathrm{HV})$ blend systems. ${ }^{28}$ Similarly, the weight-loss rates of some copolymers such as $\mathrm{P}(3 \mathrm{HB}-4 \mathrm{HB}),{ }^{8} \mathrm{P}(3 \mathrm{HB}-6 \mathrm{HH}),{ }^{36}$ and $\mathrm{P}(3 \mathrm{HB}-\mathrm{LA})^{37}$ have been also found to increase with the increase of $3 \mathrm{HB}$ unit content in these copolymers. Considering that the $\mathrm{P}(3 \mathrm{HB})$ depolymerase has lower or little activity for the degradation of the second component, observed trend is reasonable. The weight-loss of $\mathrm{AB} 90$ was more than two times faster than that of $\mathrm{P}(3 \mathrm{HB})$. Similar behavior has been found for the degradation of $\mathrm{P}(3 \mathrm{HB}-6 \mathrm{HH})^{36}$ copolymer system by $\mathrm{P}(3 \mathrm{HB})$ depolymerase, in which the weight-loss of copolymer with $3 \mathrm{HB}$ fraction of $89 \mathrm{~mol} \%$ was about ten times faster than that of $\mathrm{P}(3 \mathrm{HB})$. Similar trend has been also observed for $\mathrm{P}(3 \mathrm{HB}-4 \mathrm{HB})^{8}$ and $\mathrm{P}(3 \mathrm{HB}-\mathrm{LA}){ }^{37}$

In Figure 7 is shown the relationship of weight-loss of the CB blends with elapse time exposed to enzyme solution. The pure PBSC films show the same behavior of enzymatic degradation as that of the pure PBSA films (Figure 5). In contrast to the $\mathrm{AB}$ blend system, no $\mathrm{CB}$ blends show weight-loss that increases proportionally with time even at the first $30 \mathrm{~h}$ except the CB90 blend. Although it increases with elapse time, the rate of weight-loss decreases with the elapse time. The difference may be due to the fact that PBSC has some compatibility

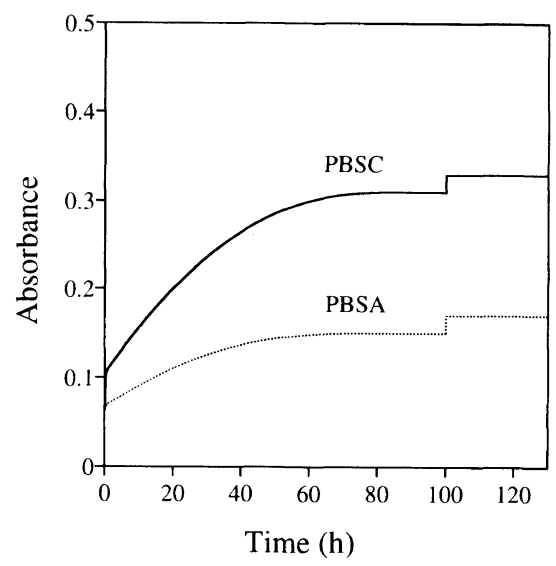

Figure 9. Change in UV absorbance of pure PBSA and PBSC film-buffer solution at the wavelength $208 \mathrm{~nm}, 37^{\circ} \mathrm{C}$ and $\mathrm{pH} \mathrm{7.5}$. The enzyme was added at 100th hour.

with $\mathrm{P}(3 \mathrm{HB})$ while PBSA does not besides the chemical structure difference between PBSA and PBSC. Figure 8 shows the dependence of the weight-loss of the $\mathrm{CB}$ blends on the $\mathrm{P}(3 \mathrm{HB})$ content during the first $16 \mathrm{~h}$. The weight-loss increases also with the increase of $\mathrm{P}(3 \mathrm{HB})$ content, except for the CB90 blend that shows exceptionally higher weight loss.

As shown in Figures 5 and 7, the films of pure PBSA and PBSC exhibited a slow weight-loss at the beginning of the experiment and their weights hardly changed after about $30 \mathrm{~h}$. It seems that their films cannot be degraded by the $\mathrm{P}(3 \mathrm{HB})$ depolymerase. In order to further clear the enzymatic degradation properties of PBSA and PBSC, the UV absorption of the buffer solutions including PBSA or PBSC films was observed at the wavelength of $208 \mathrm{~nm}$. As shown in Figure 9, the absorbance of PBSA (or PBSC) buffer solution without enzyme increased with the exposure time for the first $40 \mathrm{~h}$. This increase may be arisen mainly from simple hydrolytic degradation of polymer to water-soluble oligomer products. After keeping the film-buffer solution at $37^{\circ} \mathrm{C}$ for 3 days, the absorbance changed no longer with the exposure time. Then at the 100th hour, the enzyme was added into the buffer solution. In this case, the absorbance also did not change with the exposure time. This suggests that the $\mathrm{P}(3 \mathrm{HB})$ depolymerase is inactive to the hydrolysis of pure PBSA and PBSC films.

The UV absorption of the buffer solution including the films of the AB50 or CB50 blend was observed to confirm spectroscopically the different enzymatic degradation behavior between the $A B$ blends and the $C B$ blends. Figure 10 shows the results. For the AB50 blend, after an induction period the absorbance increased proportionally with the exposure time, indicating that the enzymatic degradation proceeded at constant rate. For the CB50 blend, it can be seen that the degradation rate decreased a little with exposure time. Thus, the results obtained by UV absorption coincide well with those obtained by the measurements of weight-loss.

\footnotetext{
${ }^{1} H$ NMR Analysis

${ }^{1} \mathrm{H}$ NMR spectra of the blend films before and after enzymatic degradation were recorded to calculate the
} 


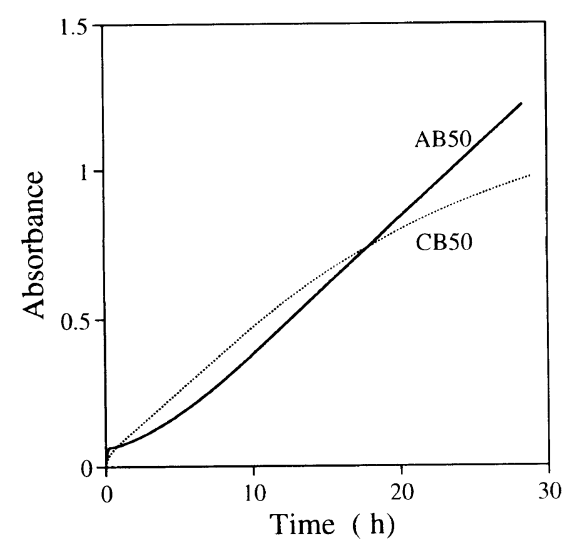

Figure 10. Change in UV absorbance of AB50 and CB50 blend film-enzyme buffer solution at the wavelength $208 \mathrm{~nm}, 37^{\circ} \mathrm{C}$ and $\mathrm{pH} 7.5$.

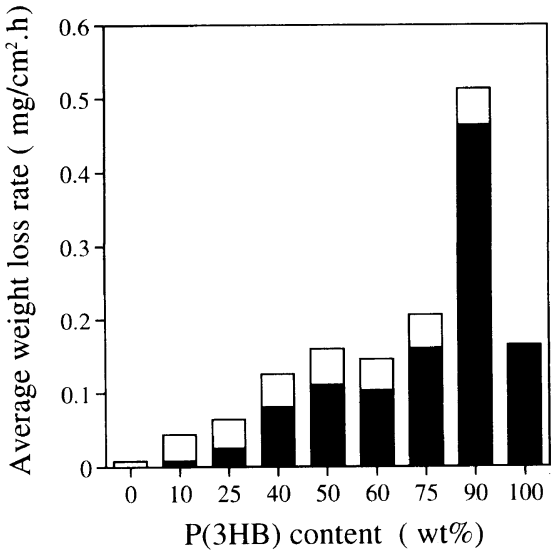

Figure 11. Average weight loss rates of each component in $\mathrm{AB}$ blend. Calculated from Table IV: (ם) P(3HB); ( $\square$ ) PBSA.

Table IV. The weight-loss and change of $\mathrm{P}(3 \mathrm{HB})$ content in $\mathrm{AB}$ blends after enzymatic degradation

\begin{tabular}{|c|c|c|c|c|c|c|c|}
\hline \multirow{2}{*}{ Blend } & \multirow{2}{*}{ Initial weight/mg } & \multirow{2}{*}{ Exposure time/h } & \multicolumn{2}{|c|}{$\mathrm{P}(3 \mathrm{HB})$ content in blend films $/ \mathrm{wt} \%$} & \multicolumn{3}{|c|}{ Weight loss/mg } \\
\hline & & & Before degradation & After degradation & Blend & $\mathrm{P}(3 \mathrm{HB})^{\mathrm{a}}$ & PBSA $^{\mathrm{a}}$ \\
\hline PBSA & 11.57 & 96 & 0 & 0 & & & 0.74 \\
\hline $\mathrm{AB} 10$ & 12.58 & 96 & 10 & 6.2 & 4.17 & 0.74 & 3.43 \\
\hline $\mathrm{AB} 25$ & 11.05 & 96 & 25 & 8.2 & 6.13 & 2.36 & 3.77 \\
\hline AB 40 & 11.46 & 57 & 40 & 0.0 & 7.14 & 4.58 & 2.56 \\
\hline $\mathrm{AB} 60$ & 7.04 & 24 & 60 & 49.6 & 3.48 & 2.46 & 1.02 \\
\hline AB75 & 10.94 & 36 & 75 & 69.4 & 7.40 & 5.75 & 1.65 \\
\hline $\mathrm{AB} 90$ & 11.51 & 8 & 90 & 89.7 & 4.10 & 3.71 & 0.39 \\
\hline $\mathrm{P}(3 \mathrm{HB})$ & 8.18 & 16 & 100 & 100 & & 2.43 & \\
\hline
\end{tabular}

${ }^{a}$ Calculated from initial blend weight, $\mathrm{P}(3 \mathrm{HB})$ content before and after degradation, blend weight loss.

Table V. The weight-loss and change of $\mathrm{P}(3 \mathrm{HB})$ content in $\mathrm{CB}$ blends after enzymatic degradation

\begin{tabular}{|c|c|c|c|c|c|c|c|}
\hline \multirow{2}{*}{ Blend } & \multirow{2}{*}{ Initial weight $/ \mathrm{mg}$} & \multirow{2}{*}{ Exposure time $/ \mathrm{h}$} & \multicolumn{2}{|c|}{$\mathrm{P}(3 \mathrm{HB})$ content in blend films $/ \mathrm{wt} \%$} & \multicolumn{3}{|c|}{ Weight loss/mg } \\
\hline & & & Before degradation & After degradation & Blend & $\mathrm{P}(3 \mathrm{HB})^{\mathrm{a}}$ & $\mathrm{PBSC}^{\mathrm{a}}$ \\
\hline $\mathrm{CB} 10$ & 13.66 & 96 & 10 & 1.9 & 1.82 & 1.14 & 0.68 \\
\hline CB25 & 13.10 & 96 & 25 & 8.0 & 4.33 & 2.57 & 1.76 \\
\hline CB40 & 13.68 & 96 & 40 & 18.8 & 4.19 & 3.69 & 0.50 \\
\hline CB50 & 15.19 & 96 & 50 & 31.8 & 5.20 & 4.42 & 0.78 \\
\hline CB60 & 11.15 & 96 & 60 & 51.2 & 4.26 & 3.16 & 1.10 \\
\hline CB75 & 13.46 & 96 & 75 & 67.0 & 7.03 & 5.79 & 1.24 \\
\hline $\mathrm{CB} 90$ & 9.55 & 8 & 90 & 88.5 & 3.10 & 2.89 & 0.21 \\
\hline $\mathrm{P}(3 \mathrm{HB})$ & 8.18 & 16 & 100 & 100 & & 2.43 & \\
\hline
\end{tabular}

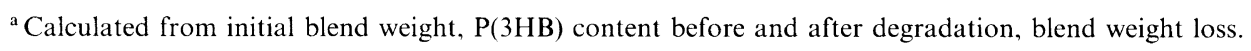

$\mathrm{P}(3 \mathrm{HB})$ contents in blend films after enzymatic degradation. The relative intensities of the proton resonances arisen from the methine group $(\mathrm{CH}(\beta))$ of $\mathrm{P}(3 \mathrm{HB})$ units $(\delta=5.2 \mathrm{ppm})$ and $-\mathrm{CH}_{2} \mathrm{O}-$ of PBSA or PBSC units $(\delta=$ $4.1 \mathrm{ppm})$ were used to estimate the $\mathrm{P}(3 \mathrm{HB})$ contents in the $\mathrm{AB}$ and $\mathrm{CB}$ blends after degradation, which are listed in Tables IV and $\mathrm{V}$, respectively.

It is clear that the $\mathrm{P}(3 \mathrm{HB})$ contents in both the $\mathrm{AB}$ and $\mathrm{CB}$ blends decreased after degradation. This result is reasonable as the $\mathrm{P}(3 \mathrm{HB})$ depolymerase is inactive to the hydrolysis of pure PBSA and PBSC. What is interesting is the weight-loss of each component in the blend films. As shown in Table IV, the amounts of weightloss of PBSA component in the AB10 and AB25 blend films after $96 \mathrm{~h}$ exposure were $3.43 \mathrm{mg}$ and $3.77 \mathrm{mg}$, re- spectively, which were about five times larger than that found in the pure PBSA film $(0.74 \mathrm{mg})$ at the same exposure time. In Table $\mathrm{V}$, the amount of weight-loss of PBSC component in the CB25 blend $(1.76 \mathrm{mg})$ was about two times larger than that in pure PBSC film after the exposure time of $96 \mathrm{~h}$. Figure 11 shows the average rate of weight-loss for each component in the $\mathrm{AB}$ blends, calculated from the data shown in Table IV. It is clear that the PBSA component in the blend showed a relatively large average weight-loss rate in all composition range comparing to pure PBSA film. The average weight-loss rate of PBSA component in the blend was about five times larger than that of pure PBSA and was about a half as that of $\mathrm{P}(3 \mathrm{HB})$ component in the AB50 blend. 


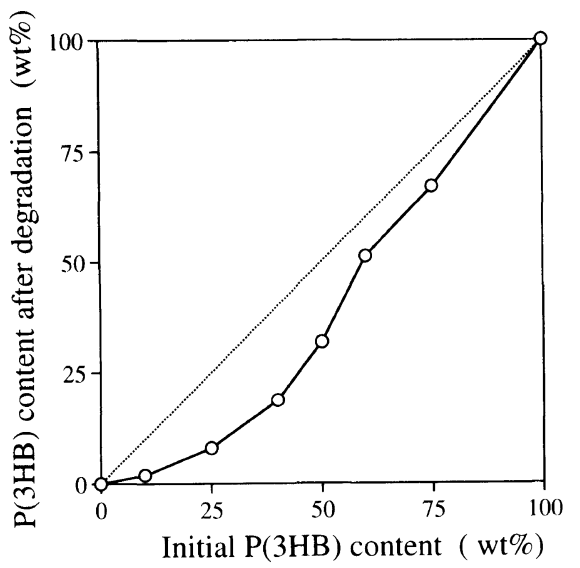

Figure 12. Plot of $\mathrm{P}(3 \mathrm{HB})$ content after $96 \mathrm{~h}$ degradation versus initial $\mathrm{P}(3 \mathrm{HB})$ content in $\mathrm{CB}$ blends.

The weight-loss of PBSA (or PBSC) component in the blends may be arisen from the following three factors: (1) simple hydrolytic degradation of polymer to watersoluble oligomer; (2) The falling off of PBSA (or PBSC) from the film. Especially for the films with high $\mathrm{P}(3 \mathrm{HB})$ contents, $\mathrm{P}(3 \mathrm{HB})$ and $\mathrm{PBSA}$ (or PBSC) should constitute the continuous and dispersed phase, respectively. So PBSA (or PBSC) will fall off from the blend film with progress in the erosion of $\mathrm{P}(3 \mathrm{HB})$; (3) Enzymatic degradation of PBSA (or PBSC) induced by the presence of $\mathrm{P}(3 \mathrm{HB})$. Studies on the chemosynthesised atactic $\mathrm{P}(R, S-3 \mathrm{HB})$ have shown that atactic $\mathrm{P}(R, S-3 \mathrm{HB})$ underwent enzymatic attack when it blended with natural $\mathrm{P}(3 \mathrm{HB})^{29}$ or $\mathrm{P}(3 \mathrm{HB}-3 \mathrm{HV}),{ }^{30}$ but it alone didn't biodegrade. Similar induced biodegradation has been also observed for chemosynthetic [ $(R, S)-\beta$-butyrolactone $]$ b-pivalolactone copolymers. ${ }^{38}$ The similar case may also occur in the $\mathrm{AB}$ and $\mathrm{CB}$ blends.

As the weight-loss of pure PBSA (or PBSC) film is small, at least the factor (1) should not be the main factor. The factor (2) may be the main ones for the blends with high $\mathrm{P}(3 \mathrm{HB})$ content but cannot be the main ones for those with low $\mathrm{P}(3 \mathrm{HB})$ content. So the factor (3) may be responsible for the large weight-loss or high weight-loss rate of PBSA component in the blend with low $\mathrm{P}(3 \mathrm{HB})$ content. It needs further studies on the degradation products to draw such a conclusion.

It has been found that the $\mathrm{P}(3 \mathrm{HB})$ depolymerase of Alcaligenes faecalis $\mathrm{T} 1$ has a hydrophobic binding domain in addition to a catalytic domain, ${ }^{39}$ and it was suggested that the enzymatic degradation take place via two steps: the first is adsorption of enzyme on the film surface and the second is hydrolysis of polymer chain into water-soluble products by the catalytic domain. ${ }^{40}$ Abe et $a l .{ }^{29}$ have attributed the observed nonbiodegradability of $\mathrm{P}(R, S-3 \mathrm{HB})$ to the difficulty of the adsorption step. The case for PBSA and PBSC may be similar.

Another fact worthy to point out is that the films of AB40 blend remain integrity even the content of $\mathrm{P}(3 \mathrm{HB})$ in blend changed to $0 \%$ after $57 \mathrm{~h}$ degradation (Table IV). This result conforms that PBSA constitutes a continuous phase in $\mathrm{AB} 40$ blend.

The $\mathrm{P}(3 \mathrm{HB})$ contents in the $\mathrm{CB}$ blends after $96 \mathrm{~h}$ degradation are also shown in Figure 12. Comparing to those before degradation, which are represented by the spotted line, it is clear that the change of $\mathrm{P}(3 \mathrm{HB})$ content is large at low $\mathrm{P}(3 \mathrm{HB})$ content while small at higher $\mathrm{P}(3 \mathrm{HB})$ content. This result may come from the change of morphology of blends with the change of $\mathrm{P}(3 \mathrm{HB})$ content.

\section{CONCLUSIONS}

$\mathrm{P}(3 \mathrm{HB})$ and PBSA and also $\mathrm{P}(3 \mathrm{HB})$ and PBSC polymers are found to be immiscible in the amorphous state. Both PBSA/P(3HB) (AB) and PBSC/P(3HB) (CB) blends show two distinct glass transition temperatures independent of composition. The radial growth rates of $\mathrm{P}(3 \mathrm{HB})$ spherulite in these blends were almost the same irrespective of the $\mathrm{P}(3 \mathrm{HB})$ content ranged from $50 \mathrm{wt} \%$ to $100 \mathrm{wt} \%$.

The biodegradation behavior by the $\mathrm{P}(3 \mathrm{HB})$ depolymerase of $\mathrm{AB}$ and $\mathrm{CB}$ blends is found to depend on the blend composition. The UV absorption experiments of the buffer solutions including PBSA or PBSC films suggested that the $\mathrm{P}(3 \mathrm{HB})$ depolymerase is inactive to the hydrolysis of both PBSA and PBSC films and so the weight-loss of pure PBSA or PBSC in $\mathrm{P}(3 \mathrm{HB})$ depolymerase solution may be arisen mainly from the simple hydrolytic degradation of polymer to watersoluble oligomer products. In general, the weight-loss rates of the blends increase with the increase of $\mathrm{P}(3 \mathrm{HB})$ content except the blend contained $90 \mathrm{wt} \% \mathrm{P}(3 \mathrm{HB})$, in which a weight-loss rate was about three times larger than pure $\mathrm{P}(3 \mathrm{HB})$ films. In the first $30 \mathrm{~h}$ degradation in the presence of $\mathrm{P}(3 \mathrm{HB})$ depolymerase, all the $\mathrm{AB}$ blends show constant weight-loss rate while no $\mathrm{CB}$ blends show the same degradation behavior except CB90 blend. This different degradation behavior may be due to the fact that PBSC has some compatibility with $\mathrm{P}(3 \mathrm{HB})$ while PBSA has not.

${ }^{1} \mathrm{H}$ NMR analysis makes it clear that $\mathrm{P}(3 \mathrm{HB})$ contents in both $\mathrm{AB}$ and $\mathrm{CB}$ blends decreased after degradation. However, what is interesting is the amounts of weightloss of PBSA component in the AB10 and AB25 blend films after $96 \mathrm{~h}$ exposure were about five times larger than that found in the pure PBSA film at the same exposure time and the average weight-loss rate of PBSA component in blend was about five times larger than that of pure PBSA. Enzymatic degradation of PBSA (or PBSC) induced by the presence of $\mathrm{P}(3 \mathrm{HB})$ may be responsible for the large weight-loss or high weight-loss rate of PBSA component in the blend with low $\mathrm{P}(3 \mathrm{HB})$ content. Further studies on the degradation products may confirm this point.

The results obtained in this paper suggest that the biodegradability of biodegradable aliphatic polyester is controllable by blending.

Acknowledgment. The authors thank Showa Highpolymer Co., Ltd. (Tokyo) for a kindly gift of Bionolle samples.

\section{REFERENCES}

1. Y. Doi, "Microbial Polyesters," VCH Publishers, New York, N.Y., 1990.

2. P. A. Holmes, in "Developments in Crystalline Polymers-2," D. 
C. Bassett, Ed., Elsevier, London, 1988, p 1.

3. A. J. Anderson and E. A. Dawes, Microbiol. Rev., 54, 450 (1990).

4. R. Sharma and A. R. Ray, J.M.S.-Rev. Macromol. Chem. Phys., C35, 327 (1995).

5. Y. Hori and A. Yamaguchi, Macromolecules, 28, 406 (1995).

6. T. Kobayashi, A. Yamaguchi, T. Hagiwara, and Y. Hori, Polymer, 36, 4707 (1995).

7. N. Koyama and Y. Doi, Macromolecules, 30, 826 (1997).

8. H. Abe, Y. Doi, H. Aoki, and T. Akehata, Macromolecules, 31, 1791 (1998).

9. P. Greco and E. Martuscelli, Polymer, 30, 1475 (1989).

10. Y. Kumagai and Y. Doi, Polym. Degrad. Stab., 36, 241 (1992).

11. N. Lotti, M. Pizzoli, G. Ceccorulli, and M. Scandola, Polymer, 34, 4935(1993).

12. M. Avella and E. Martuscelli, Polymer, 29, 1731 (1988).

13. M. Avella, E. Martuscelli, and P. Greco, Polymer, 32, 1647 (1991).

14. Y. Kumagai and Y. Doi, Polym. Degrad. Stab., 35, 87(1992).

15. M. Avella, E. Martuscelli, and M. Raimo, Polymer, 34, 3234(1993).

16. Y. Azuma, N. Yoshie, M. Sakurai, Y. Inoue, and R. Chûjô, Polymer, 33, 4763 (1992).

17. L. Zhang, C. Xiong, and X. Deng, Polymer, 37, 235 (1996).

18. N. Koyama and Y. Doi, Polymer, 38, 1589(1997).

19. N. Koyama and Y. Doi, Can. J. Microbiol., 41 (Suppl. 1), 316 (1995).

20. A. Lisuardi, A. Schoenberg, M. Gada, R. A. Gross, and S. P. McCarthy, Polym. Mater. Sci. Eng., 67, 298 (1992).

21. S. J. Organ and P. J. Barham, Polymer, 34, 459 (1993).

22. P. J. Barham, P. Barker, and S. J. Organ, FEMS Microbiol. Rev., 103, 289 (1992).

23. H. Satoh, N. Yoshie, and Y. Inoue, Polymer, 35, 286 (1994).

24. L. Finelli, M. Scandola, and P. Sadocco, Macromol. Chem. Phys., 199, 695 (1998).

25. G. Ceccorulli, M. Pizzoli, and M. Scandola, Macromolecules, 26,
6722 (1993).

26. G. Tomasi and M. Scandola, J. M. S.-Pure Appl. Polym. Sci., A32, 671(1995).

27. T. Ikejima, K. Yagi, and Y. Inoue, Macromol. Chem. Phys., in press.

28. Y. Kumagai and Y. Doi, Polym. Degrad. Stab., 37, 253 (1992).

29. H. Abe, I. Matsubara, and Y. Doi, Macromolecules, 28, 844 (1995).

30. M. Scandola, M. L. Focarrete, G. Adamus, W. Sikorska, I. Baranowska, S. Swierczek, M. Gnatowski, M. Kowalczuk, and Z. Jedlinski, Macromolecules, 30, 2568 (1997).

31. E. Takiyama, I. Niikura, and Y. Hatano, U.S. Patent, 5306 787, 1993.

32. E. Takiyama and T. Fujimaki, in "Biodegradable Plastics and Polymer," Y. Doi and K. Fukuda, Ed., Elsevier Science B. V., Amsterdam, The Netherlands, 1994, p 150.

33. Y. Shirakura, T. Fukui, T. Saito, Y. Okamoto, T. Narikawa, K. Koide, K. Tomita, T. Takemasa, and S. Masamune, Biochim. Biophys. Acta, 880, 46(1986).

34. K. Kasuya, Y. Inoue, and Y. Doi, Int. J. Biol. Macromol., 19, 35 (1996).

35. P. Barham, A. J. Keller, E. L. Otun, and P. A. Holmes, J. Mater. Sci., 19, 2781 (1984).

36. H. Abe, Y. Doi, H. Aoki, T. Akehata, Y. Hori, and A. Yamaguchi, Macromolecules, 28, 7630 (1995).

37. H. Abe, Y. Doi, Y. Hori, and T. Hagiwara, Polymer, 39, 59 (1998).

38. M. Scandola, M. L. Focarete, M. Gazzano, A. Matuszowicz, W. Sikorska, G. Adamus, P. Kurcok, M. Kowalczuk, and Z. Jedlinski, Macromolecules, 30, 7743 (1997).

39. T. Fukui, T. Narikawa, K. Miwa, Y. Shirakura, T. Saito, and K. Tomita, Biochim. Biophys. Acta, 952, 164 (1988).

40. K. Mukai, K. Yamada, and Y. Doi, Int. J. Biol. Macromol., 15, 361 (1993). 